\title{
Parental Decision and Intent Towards COVID-19 Vaccination in Children With Asthma.
}

An Econometric Analysis

\section{CIRANO}

Allier savoir et décision

OLIVIER DROUIN

CLAUDE MONTMARQUETTE

ALEXANDRE PRUD'HOMME

YANN ARNAUD

PIERRE FONTAINE

ROXANE BORGÈS DA SILVA 


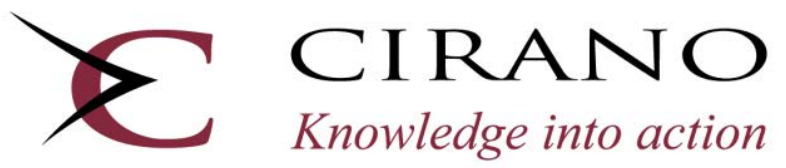

Center for Interuniversity Research and Analysis on Organizations

The purpose of the Working Papers is to disseminate the results of research conducted by CIRANO research members in order to solicit exchanges and comments. These reports are written in the style of scientific publications. The ideas and opinions expressed in these documents are solely those of the authors.

Les cahiers de la série scientifique visent à rendre accessibles les résultats des recherches effectuées par des chercheurs membres du CIRANO afin de susciter échanges et commentaires. Ces cahiers sont rédigés dans le style des publications scientifiques et n'engagent que leurs auteurs.

CIRANO is a private non-profit organization incorporated under the Quebec Companies Act. Its infrastructure and research activities are funded through fees paid by member organizations, an infrastructure grant from the government of Quebec, and grants and research mandates obtained by its research teams.

Le CIRANO est un organisme sans but lucratif constitué en vertu de la Loi des compagnies du Québec. Le financement de son infrastructure et de ses activités de recherche provient des cotisations de ses organisations-membres, d'une subvention d'infrastructure du gouvernement du Québec, de même que des subventions et mandats obtenus par ses équipes de recherche.

\section{CIRANO Partners - Les partenaires du CIRANO}

Corporate Partners - Partenaires corporatifs

Autorité des marchés financiers

Bank of Canada

Bell Canada

BMO Financial Group

Business Development Bank of Canada

Caisse de dépôt et placement du Québec

Desjardins Group

Énergir

Hydro-Québec

Innovation, Science and Economic Development Canada

Intact Financial Corporation

Manulife Canada

Ministère de l'Économie, de la Science et de l'Innovation

Ministère des finances du Québec

National Bank of Canada

Power Corporation of Canada

PSP Investments

Rio Tinto

Ville de Montréal

Academic Partners - Partenaires universitaires

Concordia University

École de technologie supérieure

École nationale d'administration publique

HEC Montréal

McGill University

National Institute for Scientific Research

Polytechnique Montréal

Université de Montréal

Université de Sherbrooke

Université du Québec

Université du Québec à Montréal

Université Laval

CIRANO collaborates with many centers and university research chairs; list available on its website. Le CIRANO collabore avec de nombreux centres et chaires de recherche universitaires dont on peut consulter la liste sur son site web.

(C) March 2021. Olivier Drouin, Claude Montmarquette, Alexandre Prud'homme, Yann Arnaud, Pierre Fontaine, Roxane Borgès Da Silva. All rights reserved. Tous droits réservés. Short sections may be quoted without explicit permission, if full credit, including $($ ) notice, is given to the source. Reproduction partielle permise avec citation du document source, incluant la notice $\subseteq$.

The observations and viewpoints expressed in this publication are the sole responsibility of the authors; they do not necessarily represent the positions of CIRANO or its partners. Les idées et les opinions émises dans cette publication sont sous l'unique responsabilité des auteurs et ne représentent pas nécessairement les positions du CIRANO ou de ses partenaires. 


\title{
Parental Decision and Intent Towards COVID-19 Vaccination in Children With Asthma. An Econometric Analysis
}

\author{
Olivier Drouin *, Claude Montmarquette ', Alexandre Prud'homme *, \\ Yann Arnaud $\$$, Pierre Fontaine **, Roxane Borgès Da Silva †t
}

\begin{abstract}
Résumé
Objective. Vaccination will be instrumental in controlling the COVID-19 pandemic, and vaccination of children will be necessary to achieve herd immunity. Given that children with chronic health conditions may be at increased risk of COVID-19, it is crucial to understand factors influencing parental decisions about whether to have their child vaccinated. The study objectives were to measure parental intent to have their child with asthma vaccinated against COVID-19 and identify the determinants of their vaccination decision.

Study design. This study is based on a cross-sectional exploratory observational online survey assessing parents' risk perception in the context of COVID-19.

Methods. In this study conducted in August 2020, the primary outcome was parent's answer to the question on their intention to get their child vaccinated if a vaccine against COVID-19 was available. Participants were also asked about their intention to get vaccinated themselves. Independent variables studied included sociodemographic, clinical data (e.g. presence of other chronic diseases), psychological, cognitive and risk perception related to COVID-19. Simultaneous equations models (3SLS) and seemingly unrelated regressions model (SUR) were carried out to identify factors associated with intention to have the child vaccinated and participants' intention to get vaccinated themselves against COVID-19.

Results. A total of 305 participants completed the survey. Overall, 19.1\% of participants reported being unlikely or very unlikely to vaccinate their child against COVID-19 if a vaccine was available. Similarly, $21.0 \%$ were unlikely or very unlikely to get vaccinated themselves. The following factors were significantly $(\mathrm{p} \leq 0.05)$ associated with parents' decision to have their child vaccinated: parental level of education, employment status, sex of the child, presence of other chronic diseases, whether or not the child had been vaccinated against influenza in the past, parental anxiety, and consultation with a health professional since the beginning of the pandemic. There was a strong relationship between likelihood of not intending to have one's child vaccinated and personal intent not to get vaccinated.

Conclusion. These findings are essential in planning for the communication and dissemination of COVID-19 vaccination information to parents, especially for children with asthma or other chronic medical conditions.
\end{abstract}

Keywords/Mots-clés: COVID-19, Vaccine, Asthmatic Children, Parental Decisions, Econometric Modeling

\footnotetext{
* MDCM MSc MPH. Division of General Pediatrics, Department of Pediatrics, CHU Sainte-Justine. 3175 chemin de la CôteSainte-Catherine, Montréal (QC), Canada, H3T 1C5. Department of Social and Preventive Medicine, School of Public Health, University of Montreal. 7101 avenue du Parc, Third floor (Office 3029), Montréal (QC), Canada, H3N 1 X9.

$\dagger \mathrm{PhD}$. CIRANO (Centre interuniversitaire de recherche en analyse des organisations). 1130 rue Sherbrooke Ouest \#1400, Montréal (QC), Canada, H3A 2M8. Department of Economics, Université de Montréal. 3150 rue Jean-Brillant (Pavillon LionelGroulx), Montréal (QC), Canada, H3T 1N8.

\$ BSc. CIRANO. Department of Management, Evaluation and Health Policy, School of Public Health, University of Montreal. 7101 avenue du Parc, Third Floor (Office 3076), Montréal (QC), Canada, H3N 1 X9.

$\S$ MSc. CIRANO. School of Economics \& CERDI, University of Clermont-Auvergne. 26 Avenue Léon Blum, 63000 ClermontFerrand, France.

${ }^{* *}$ B.Eng., MD (candidate). Faculty of Medicine, University of Montreal. 2900 boulevard Edouard-Montpetit (Pavillon RogerGaudry), Montréal (QC), Canada, H3T 1J4.

$\Uparrow$ PhD. CIRANO. Department of Management, Evaluation and Health Policy, School of Public Health, University of Montreal.
} 


\section{Manuscript}

\section{Background}

As the COVID-19 pandemic spreads around the world, much hope and effort have been invested in finding a vaccine (1). However, developing an effective COVID-19 vaccine will be only a first step in achieving immunity and controlling the pandemic (2). Large-scale vaccination efforts will be required, and governments worldwide are currently devising vaccination strategies. One key element of any strategy is the acceptance of the vaccine by the general public. Worryingly, surveys suggest that people's willingness to get vaccinated against COVID-19 is far from universal (3).

Vaccination is one of the safest and most cost-effective public health interventions available (4-7). Children's routine vaccinations, including against pneumococcus, polio, and measles, are public health success stories. A large majority of people accept children's routine immunization. Yet, there is significant variation in vaccine acceptance, owing to a variety of vaccine-related and individual factors, which may have relevance to a future COVID-19 vaccine for children (8).

Among existing vaccines, more recently developed ones, such as the human papillomavirus vaccine, have lower acceptance rates and are more prone to generate vaccine hesitancy (9). Similarly, vaccines requiring yearly administration or those of uncertain effectiveness (such as the annual influenza vaccine) have lower rates of uptake (10). In contrast, the perception of a vaccine as being part of routine vaccination, instead of part of a specific vaccination campaign, leads to greater acceptance (11).

\section{Likelihood of COVID-19 vaccine uptake in adults}

In an extensive survey conducted in 19 countries, only $71.5 \%$ of adult participants said they were likely to accept a COVID-19 vaccine, with a wide variation across countries (3). Factors associated with adults' willingness to accept COVID-19 vaccination have been the subject of a variety of recent surveys and studies worldwide (12,13). Of note, surveys on COVID-19 vaccine acceptance are based on the availability of a "proven, safe, and effective vaccine," which may not be guaranteed, at least initially. Social determinants of COVID-19 vaccination intention include socioeconomic status, age, ethnicity, and political ideology (13-17). In general, greater acceptance is found among women, older adults, those with higher education, and those with greater trust in government (3).

Other individual-level determinants of intention to get vaccinated include COVID-19 risk perception, knowledge about the disease, and understanding of the impact of vaccination as a preventive measure $(18,19)$.

\section{Determinants of child vaccination against COVID-19}

Comparatively, factors associated with willingness to have one's child vaccinated have seldom been studied in the context of a pandemic. Few studies have examined parental intention to have their child vaccinated against influenza during the COVID-19 pandemic $(20,21)$. Recent studies by Goldman et al. based on cross-sectional surveys showed that less than $50 \%$ of parents would be willing to have their child vaccinated against COVID-19 (18). 
One study conducted with a convenience sample of parents in England showed that most parents said they would likely accept a COVID-19 vaccine, both for themselves and for their children (14). In that study, visible minorities were less likely to report wanting to be vaccinated against COVID-19, as were participants of lower socioeconomic status. However, the study did not systematically examine mechanistic explanations for the differences between sociodemographic groups. In open-text responses and interviews, the primary motivation given for getting vaccinated was self-protection, while concerns regarding a rapidly developed vaccine's safety were a predominant worry (14).

In a study of children presenting to pediatric emergency departments from March to May $2020,65 \%$ of caregivers reported that they intended to have their child vaccinated against COVID-19 (18). Determinants of a higher likelihood of reporting intent to vaccinate were older children, children without chronic disease, recent history of influenza vaccination, and caregivers' concerns about COVID-19 (18).

Finally, regarding parents' acceptance of a COVID-19 vaccine for themselves, an Australian study conducted during the first wave of the pandemic showed that $16.7 \%$ of parents were unsure, and $7.6 \%$ were unwilling to accept a COVID-19 vaccine. Of those, the vast majority were concerned about vaccine efficacy and safety, while one in four believed that the vaccine was unnecessary (22).

\section{Vaccination in children with asthma}

Asthma is a common chronic respiratory disease, affecting one in ten children, making it one of the most common chronic diseases of childhood $(23,24)$. Children with asthma tend to have a more severe respiratory virus infection presentation, especially among those with poorly controlled disease. As such, they represent an important yet understudied group with regards to vaccination.

Regarding influenza vaccination in children with asthma, studies have shown that children were more likely to be vaccinated if they were younger, if parents believed the vaccine had good efficacy, and if parents had few worries about potential side effects. Interestingly, asthma control level did not appear to be a significant factor in parents' decision to vaccinate (25). Importantly, children were much more likely to get vaccinated if the vaccine had been recommended by a physician (26). Studies performed during the H1N1 pandemic also showed that parent-reported intent to vaccinate among children with asthma was low, with no effect of asthma control. Still, prior vaccination for influenza and beliefs and attitudes regarding the influenza $\mathrm{A} / \mathrm{H} 1 \mathrm{~N} 1$ vaccine were significant determinants of their decision (27). In this context, physician recommendation was a decisive factor influencing intent to have a child vaccinated. To date, we are not aware of any study examining determinants of parents' decision to have their child with asthma vaccinated against COVID-19.

\section{Behavioral economics}

To ensure that large-scale COVID-19 vaccination efforts will be successful and to guarantee vaccine uptake, it is necessary to go beyond sociodemographic characteristics and understand the determinants of people's decisions to get vaccinated. Differences in acceptance between age groups or across socioeconomic statuses are likely due to other factors, such as risk perception, numeracy, or risk tolerance. It is essential to understand those other factors, given that, as opposed to age and sex, they are malleable and amenable to intervention. Behavioral 
economics examines determinants of behaviors beyond expected utility and can help us understand people's decisions made under uncertainty. It can also help us comprehend difficult and puzzling behaviors, such as vaccine hesitancy and vaccine refusal. Beyond its descriptive capacity, the field can also shed light on important potential interventions to encourage socially desirable behaviors like vaccination $(28,29)$. The importance of understanding behavioral aspects of COVID-19 vaccination has been recognized by the World Health Organization, which recently published a technical report on "Behavioral Considerations for Acceptance and Uptake of COVID-19 Vaccines" (30).

\section{Objectives}

The study objectives were to measure parental intent to have their asthmatic child vaccinated against COVID-19 and identify the determinants of their vaccination decision.

\section{Methods}

\section{Study population and data collection}

The participants in this study were parents of children with asthma, followed in a specialized asthma clinic of a pediatric tertiary care center of a large city in Canada. Only parents that had previously indicated to the asthma clinic their interest in participating in studies were invited to participate to the study $(\mathrm{n}=580)$.

This study used a de-identified online cross-sectional survey conducted between July 30 and August 17, 2020. All potential participants were first invited by email to complete the survey via a secure and personalized hyperlink leading to online questionnaire (Lime Survey). Up to two reminders were sent by email in the following 10 days.

The ethics committee of the CHU Sainte-Justine has approved the study and the data collection procedures (\# 2021-3032). The informed consent (electronic consent) of participants was obtained before completing the online questionnaire. All methods were performed in accordance with the relevant guidelines and regulations.

\section{Dependent variables}

Intention to get vaccinated against COVID-19

Our primary dependent variable was parents' stated intention to have their child vaccinated, in response to the following question: "If a vaccine for COVID-19 was available today, what is the likelihood that you would have your child vaccinated?" Participants answered on a 4-point Likert scale ranging from Very Unlikely to Unlikely, Likely, and Very Likely, with a response option for "I don't know or refuse to answer." As a secondary outcome, we also asked parents if they themselves intended to get vaccinated, using the same answer categories.

\section{Independent variables}

Sociodemographic

Sociodemographic variables included the parent's sex, age, level of education, work status, and region of residence. The sex and age of the child were also covariates. 


\section{Clinical}

Participants were asked to report on their child's asthma control using the validated Asthma Control Test that has been used in other COVID studies (31-33). We enquired about consulting with a physician or health professional at the onset of the pandemic and whether the child had been vaccinated against influenza in the previous year. We also asked parents whether their child had any other chronic medical conditions (34).

Psychological

We evaluated participants' personal worries during the COVID-19 pandemic with the Lavoie and Bacon survey questionnaire on COVID-19 Awareness and Responses (35). Participants' anxiety was measured using the General Anxiety Disorder (GAD-7) scale, a short validated scale used in other COVID-related publications (32).

Risk perception

To understand how the risk of COVID-19 is perceived, we asked parents what they thought was the likelihood that their child would be infected with COVID-19 in the coming months. Parents were also asked about their perceived level of control in preventing COVID-19 infection in their child (36). Finally, parents were asked if they knew someone who had been infected with COVID-19.

Cognitive

Participants were administered Frederick's Cognitive Reflection Test (37). The test measures an individual's ability to think "slow" rather than "fast," using the terminology of Kahneman (38). Individuals who read and answer quickly (fast thinking) are less likely to answer correctly. Participants were also asked to complete Jappelli's numeracy test (39).

\section{Model specifications}

The survey data have been analyzed with appropriate econometric models. Causality issues are discussed, with a path analysis of parents' decisions to vaccinate their child and themselves.

The relationship between the two dependent variables (intent to have the child vaccinated, and parents' intent to get vaccinated themselves), along with the proper independent variables for both equations suggests that different econometric models need to be explored to account for the causality issue.

As mentioned earlier, both dependent variables are measured using a 4-point Likert scale, with a response option for "I don't know or refuse to answer." We kept the individuals in our sample that chose this last answer and opted for a 5-point Likert scale ordered in the following way: I do not know or refuse to answer, unlikely, very unlikely, likely, very likely. ${ }^{1}$

Figure 1 illustrates the different causality issues involved in parents' intention to have their children and themselves vaccinated against COVID-19, emphasizing the directions of causation.

\footnotetext{
${ }^{1}$ Descriptive statistics suggest that participants choosing the "I don't know or refuse to answer" category or the "Very unlikely" category share a fair number of sociodemographic characteristics.
} 


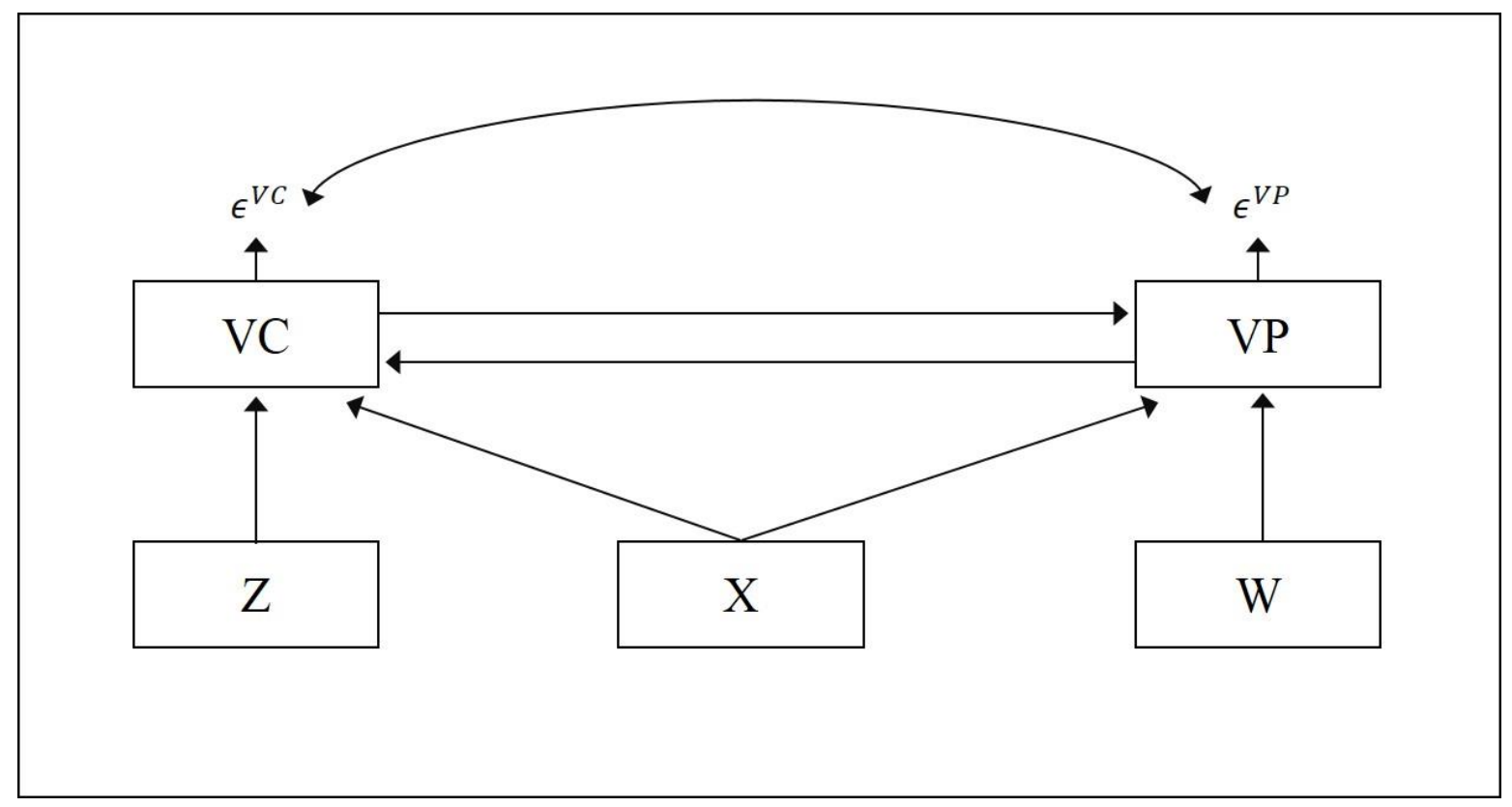

Figure 1: Path analysis of parents' intentions to have their child and themselves vaccinated

The general model is a simultaneous equations model between VC (vaccination of a child) and VP (vaccination of a parent), one influencing the other and vice-versa and with correlated error terms $\epsilon^{V C}$ and $\epsilon^{V P}$. X is a set of exogenous variables shared by both decisions. $\mathrm{Z}$ and $\mathrm{W}$ are sets of exogenous variables affecting the VC decision only and the VP decision only. Three-stage least squares (3SLS) will estimate this general model by linearizing the five categories of the dependent variables in $0,1,2,3,4$ instead of keeping their qualitative ordering.

Other causality hypotheses are obtained by removing some arrows between the dependent variables. For example, considering the causality running from the decision to vaccinate a child as an explanation for the parents' decision to accept a vaccine for themselves will remove the arrow in the other direction leading to a recursive model. Here, a two-step procedure will first run an ordered probit on a parent's decision to vaccinate a child and then use the predicted values (in linear terms) to explain the decision to accept a vaccine for herself or himself. If causality runs in the other direction, the arrow from VC to VP is removed. The model is estimated with a two-step procedure as described above. Finally, supposing the two vaccination decisions are independent, then we estimate the model with a seemingly unrelated regressions model (SUR) to maintain the hypothesis that the error terms are correlated. Here, we need to linearize the five categories of the dependent variables in $0,1,2,3,4$, as for the 3SLS model.

While the 3SLS model nests the SUR specification, the other models are not nested. The goal of estimating all four models is to come up with robust results relative to the exogenous variables. Our preferred model is presented in detail in the text, and one model is shown in 
the Appendix: Table A1). The results of the other models are briefly discussed (all estimates are available on request).

\section{Results}

Descriptive and summary statistics

In total, 305 participants completed the survey among the 580 contacted, for a response rate of $52.6 \%$.

Table 1 shows that $63 \%$ of parents are likely or very likely to have their child vaccinated, and $64 \%$ are likely to get themselves vaccinated.

Table 1: Distribution (\%) of parents' answers about the likelihood of accepting a vaccine for their child and themselves $(n=305)$

\begin{tabular}{lccccc}
\hline & $\begin{array}{c}\text { I don't } \\
\text { know }\end{array}$ & $\begin{array}{c}\text { Very } \\
\text { unlikely }\end{array}$ & Unlikely & Likely & $\begin{array}{c}\text { Very } \\
\text { likely }\end{array}$ \\
\hline $\begin{array}{l}\text { Parents' intention to have their asthmatic } \\
\text { child vaccinated against COVID-19 }\end{array}$ & 17.0 & 12.5 & 6.6 & 19.7 & 44.3 \\
\hline $\begin{array}{l}\text { Parents' intention to have themselves } \\
\text { vaccinated against COVID-19 }\end{array}$ & 15.1 & 14.1 & 6.9 & 18.4 & 45.6 \\
\hline
\end{tabular}

Table 2 indicates that most of our participants were mothers $(94.4 \%)$. With $68.5 \%$ of participants reporting a university level of education, our sample, while biased, concerns a segment of the population more likely to be better informed about vaccination. 


\begin{tabular}{|c|c|c|c|}
\hline & & & $\%$ \\
\hline \multirow{17}{*}{$\begin{array}{l}\text { Sociodemographic } \\
\text { characteristics }\end{array}$} & \multirow{2}{*}{ Sex of parent } & Male & 5.6 \\
\hline & & Female & 94.4 \\
\hline & \multirow{3}{*}{ Age of parent } & Under 35 & 21.3 \\
\hline & & 35 to 44 & 55.7 \\
\hline & & 45 and over & 23.0 \\
\hline & \multirow{3}{*}{ Level of education } & Secondary or less & 18.7 \\
\hline & & College (CEGEP) & 12.8 \\
\hline & & University & 68.5 \\
\hline & \multirow{2}{*}{ Employment status } & Inactive & 20.7 \\
\hline & & Active & 79.3 \\
\hline & \multirow{2}{*}{ Region of residence } & Montreal & 52.5 \\
\hline & & Other region & 47.5 \\
\hline & \multirow{2}{*}{ Sex of child } & Male & 59.0 \\
\hline & & Female & 41.0 \\
\hline & \multirow{3}{*}{ Age of child } & 5 and under & 26.6 \\
\hline & & 6 to 10 & 43.6 \\
\hline & & 11 and over & 29.8 \\
\hline \multirow{8}{*}{$\begin{array}{l}\text { Clinical } \\
\text { characteristics }\end{array}$} & \multirow{2}{*}{ Perceived control of child's asthma } & Less controlled & 15.7 \\
\hline & & More controlled & 84.3 \\
\hline & \multirow{2}{*}{ Child has another chronic disease } & No & 94.8 \\
\hline & & Yes & 5.2 \\
\hline & \multirow{2}{*}{ Child was vaccinated against influenza last year } & No & 69.8 \\
\hline & & Yes & 30.2 \\
\hline & \multirow{2}{*}{ Consultation with a health professional } & No & 31.1 \\
\hline & & Yes & 68.9 \\
\hline \multirow{13}{*}{ Risk perception } & \multirow{3}{*}{ Level of general anxiety } & Lower & 63.3 \\
\hline & & Average & 25.2 \\
\hline & & Higher & 11.5 \\
\hline & \multirow{3}{*}{ Level of concern regarding COVID-19 } & Lower & 9.5 \\
\hline & & Average & 35.4 \\
\hline & & Higher & 55.1 \\
\hline & \multirow{2}{*}{$\begin{array}{l}\text { Perceived control of child's risk of infection } \\
\text { with COVID-19 }\end{array}$} & Less controlled & 37.0 \\
\hline & & More controlled & 63.0 \\
\hline & \multirow{2}{*}{$\begin{array}{l}\text { Know someone that has been affected by } \\
\text { COVID-19 }\end{array}$} & No & 47.9 \\
\hline & & Yes & 52.1 \\
\hline & \multirow{3}{*}{ Perceived risks of infection with COVID-19 } & $50 \%$ & 39.7 \\
\hline & & Less than $50 \%$ & 38.0 \\
\hline & & More than $50 \%$ & 22.3 \\
\hline \multirow{6}{*}{$\begin{array}{l}\text { Cognitive } \\
\text { characteristics }\end{array}$} & \multirow{2}{*}{ Numeracy level } & Lower & 60.3 \\
\hline & & Higher & 39.7 \\
\hline & \multirow{2}{*}{ Cognitive skill } & Lower & 74.8 \\
\hline & & Higher & 25.2 \\
\hline & \multirow{2}{*}{ Risk tolerance } & Aversion & 77.0 \\
\hline & & Propensity & 23.0 \\
\hline
\end{tabular}




\section{Econometric results}

The general model estimated by 3SLS stressed the strong relationship between the two decisions concerning vaccination (results not shown). ${ }^{2}$ However, only two exogenous variables were statistically significant: living in the Montreal region and parents with a high numeracy level. Keeping the causality in both directions among the decision variables rendered the other determinants meaningless.

The SUR model eliminated the direct relationship between the two decisions except for the error terms. It yielded information on the role of the exogenous variables. For the decision concerning whether or not to have a child vaccinated, the coefficient estimates of the following exogenous variables had a positive effect and were statistically significant at the $5 \%$ level or better: the parent reports a university level of education, is currently active in the labor market, and the child was vaccinated for the flu last year. With a $6.8 \%$ level of significance, parents that had consulted with a health professional also had a higher probability of accepting the COVID-19 vaccine for their child.

For the decision about whether or not to get vaccinated themselves, parents with a university level of education, currently active in the labor market, and with a high numeracy level had a higher probability of accepting the COVID-19 vaccine. With a $6.3 \%$ level of significance, parents expressing a high level of concern regarding COVID-19 also had a higher probability of accepting a COVID-19 vaccine. Note that SUR estimated the correlation between the error terms at 0.852 .

Next, we consider a single causality direction between the independent variables with recursive two-step procedure models (the two-step procedure accounts for correlated error terms). One model assumes the direction of causality running from the decision to have the child vaccinated as the causal factor to explain their own decision to be vaccinated. A second model reverses the direction of causality. Both models are estimated with ordered probit using the 5-point Likert scale.

In light of the previous results and those of the next model, Table 3 presents the results for our preferred models, assuming that the decision regarding the child explains the parents' vaccination decision.

\footnotetext{
${ }^{2}$ Confirming the substantive relationship between the two vaccination variables following a Cramer's V coefficient of 0.827 .
} 


\begin{tabular}{|c|c|c|c|c|c|c|}
\hline & & & \multicolumn{2}{|c|}{ Child's model } & \multicolumn{2}{|c|}{ Parent's model } \\
\hline & & & Coef. & $\mathrm{p}$ & Coef. & $\mathrm{p}$ \\
\hline \multicolumn{3}{|c|}{$\begin{array}{l}\text { Parents' intention that their child be vaccinated against COVID } \\
\text { (linear prediction) }\end{array}$} & \multicolumn{2}{|c|}{ Not included } & 0.965 & $<0.001$ \\
\hline \multirow{10}{*}{$\begin{array}{l}\text { Sociodemographic } \\
\text { characteristics }\end{array}$} & Sex of parent (ref.: Male) & Female & 0.431 & 0.110 & -0.164 & 0.583 \\
\hline & \multirow{2}{*}{ Age of parent (ref.: Under 35) } & 35 to 44 & 0.040 & 0.806 & 0.024 & 0.880 \\
\hline & & 45 and over & -0.178 & 0.446 & -0.103 & 0.602 \\
\hline & \multirow{2}{*}{ Level of education (ref.: Secondary or less) } & College (CEGEP) & 0.175 & 0.460 & 0.074 & 0.759 \\
\hline & & University & 0.563 & 0.003 & 0.069 & 0.728 \\
\hline & Employment status (ref.: Inactive) & Active & 0.603 & 0.001 & -0.017 & 0.931 \\
\hline & Region of residence (ref.: Other regions) & Montreal & 0.217 & 0.122 & 0.134 & 0.333 \\
\hline & Sex of child (ref.: Male) & Female & 0.341 & 0.019 & Not & luded \\
\hline & \multirow{2}{*}{ Age of child (ref.: 5 and under) } & 6 to 10 & 0.030 & 0.869 & \multirow{2}{*}{\multicolumn{2}{|c|}{ Not included }} \\
\hline & & 11 and over & 0.368 & 0.100 & & \\
\hline \multirow[t]{4}{*}{$\begin{array}{l}\text { Clinical } \\
\text { characteristics }\end{array}$} & $\begin{array}{l}\text { Perceived control of child's asthma (ref:: } \\
\text { Less controlled) }\end{array}$ & More controlled & 0.072 & 0.726 & \multicolumn{2}{|c|}{ Not included } \\
\hline & Child has another chronic disease (ref.: No) & Yes & 0.565 & 0.028 & \multicolumn{2}{|c|}{ Not included } \\
\hline & $\begin{array}{l}\text { Child was vaccinated against influenza last } \\
\text { year (ref.: No) }\end{array}$ & Yes & 0.789 & $<0.001$ & \multicolumn{2}{|c|}{ Not included } \\
\hline & $\begin{array}{l}\text { Consultation with a health professional } \\
\text { (ref.: No) }\end{array}$ & Yes & 0.405 & 0.009 & \multicolumn{2}{|c|}{ Not included } \\
\hline \multirow[t]{4}{*}{ Psychological } & \multirow{2}{*}{ Level of general anxiety (ref.: Lower) } & Average & -0.038 & 0.833 & -0.089 & 0.610 \\
\hline & & Higher & 0.493 & 0.046 & -0.092 & 0.705 \\
\hline & \multirow{2}{*}{$\begin{array}{l}\text { Level of concern regarding COVID-19 } \\
\text { (ref.: Lower) }\end{array}$} & Average & 0.324 & 0.147 & -0.140 & 0.514 \\
\hline & & Higher & 0.099 & 0.654 & 0.033 & 0.878 \\
\hline \multirow[t]{4}{*}{ Risk perception } & $\begin{array}{l}\text { Know someone that has been affected by } \\
\text { COVID (ref.: No) }\end{array}$ & Yes & \multicolumn{2}{|c|}{ Not included } & 0.021 & 0.883 \\
\hline & $\begin{array}{l}\text { Perceived control of child's risk of infection } \\
\text { with COVID-19 (ref.: Less controlled) }\end{array}$ & More controlled & 0.033 & 0.813 & \multicolumn{2}{|c|}{ Not included } \\
\hline & \multirow{2}{*}{$\begin{array}{l}\text { Perceived risks of infection with COVID-19 } \\
\text { (ref.: } 50 \%)\end{array}$} & Less than $50 \%$ & -0.217 & 0.168 & \multirow{2}{*}{\multicolumn{2}{|c|}{ Not included }} \\
\hline & & More than $50 \%$ & -0.101 & 0.601 & & \\
\hline \multirow{5}{*}{$\begin{array}{l}\text { Cognitive } \\
\text { characteristics }\end{array}$} & Numeracy level (ref.: Lower) & Higher & 0.208 & 0.204 & 0.127 & 0.439 \\
\hline & Cognitive skill (ref.: Lower) & Higher & 0.077 & 0.667 & -0.020 & 0.913 \\
\hline & Risk tolerance (ref.: Aversion) & Propensity & 0.209 & 0.171 & -0.043 & 0.780 \\
\hline & & og pseudolikelihood & \multicolumn{2}{|c|}{-384} & \multicolumn{2}{|c|}{-381} \\
\hline & & Pseudo R2 & \multicolumn{2}{|c|}{0.114} & \multicolumn{2}{|c|}{0.117} \\
\hline
\end{tabular}

In this model, the decision about whether to vaccinate a child is assumed to depend on exogenous factors only (the first step in the procedure). Seven variables present coefficient estimates reaching statistical significance at the level of $5 \%$ or better and with their expected sign: parental education, employment status, sex of the child, presence of other chronic diseases, child had been vaccinated against influenza in the past, parental anxiety, and consultation with a health professional since the beginning of the pandemic. We note that four of those variables were identified with the SUR model as statistically significant for robustness. 
The probability that a parent will agree to be vaccinated (parents' model, second step) is exclusively explained by the predicted values (linear predictions) of their decision to have their child vaccinated.

Table 4 illustrates the factors influencing the predicted parents' intention that their child with asthma be vaccinated against COVID-19 based on that model.

Looking at each column, we can see which variables most influenced parents' decision to have their child vaccinated. For example, parents with a secondary education or less have a $36.4 \%$ probability of not knowing or refusing to state whether or not they intend to have their child vaccinated. This probability reaches $38.6 \%$ if the parent is currently inactive in the labor market. On the other hand, parents with a university education have a likelihood of $53.6 \%$ of having their child vaccinated.

The results shown in Table 4 can also be considered line by line. For example, parents who reported a high level of anxiety have a 5.9\% probability of belonging to the category "I don't know or refuse to answer" but a $67.5 \%$ probability of answering "Very likely" to have their child vaccinated. Similar differences can be seen when the child has another chronic disease and was vaccinated against influenza in the previous year. Conversely, parents with an education level of "Secondary or less" are 15.1 percentage points more likely to be in the "I don't know or refuse to answer" category than in the "Very likely" category. 
Table 4: Predicted distributions (\%) of parents' intention to have their asthmatic child vaccinated against COVID-19

\begin{tabular}{|c|c|c|c|c|c|c|c|}
\hline & & & $\begin{array}{c}\text { I don't } \\
\text { know } \\
\operatorname{Pr}\left(\mathrm{IF}_{\mathrm{i}}=0\right)\end{array}$ & $\begin{array}{c}\text { Very } \\
\text { unlikely } \\
\operatorname{Pr}\left(\mathrm{IF}_{\mathrm{i}}=1\right)\end{array}$ & $\begin{array}{c}\text { Unlikely } \\
\operatorname{Pr}\left(\mathrm{IF}_{\mathrm{i}}=2\right)\end{array}$ & $\begin{array}{c}\text { Likely } \\
\operatorname{Pr}\left(\mathrm{IF}_{\mathrm{i}}=3\right)\end{array}$ & $\begin{array}{l}\text { Very likely } \\
\operatorname{Pr}\left(\mathrm{IF}_{\mathrm{i}}=4\right)\end{array}$ \\
\hline \multirow{17}{*}{$\begin{array}{l}\text { Sociodemographic } \\
\text { characteristics }\end{array}$} & \multirow{2}{*}{ Sex of parent } & Male & 34.5 & 15.9 & 7.4 & 18.1 & 24.0 \\
\hline & & Female & 16.0 & 12.0 & 6.7 & 20.0 & 45.4 \\
\hline & \multirow{3}{*}{ Age of parent } & Under 35 & 17.2 & 12.3 & 6.8 & 20.0 & 43.6 \\
\hline & & 35 to 44 & 14.4 & 11.2 & 6.4 & 19.7 & 48.4 \\
\hline & & 45 and over & 23.6 & 14.2 & 7.3 & 19.9 & 35.0 \\
\hline & \multirow{3}{*}{ Level of education } & Secondary or less & 36.4 & 16.6 & 7.6 & 18.1 & 21.3 \\
\hline & & College (CEGEP) & 26.4 & 15.4 & 7.7 & 20.2 & 30.3 \\
\hline & & University & 10.7 & 10.0 & 6.0 & 19.7 & 53.6 \\
\hline & \multirow{2}{*}{ Employment status } & Inactive & 38.6 & 16.4 & 7.4 & 17.3 & 20.4 \\
\hline & & Active & 12.4 & 10.7 & 6.3 & 19.7 & 50.9 \\
\hline & \multirow{2}{*}{ Region of residence } & Other regions & 21.5 & 13.8 & 7.2 & 20.0 & 37.4 \\
\hline & & Montreal & 13.2 & 10.9 & 6.3 & 19.6 & 50.0 \\
\hline & \multirow{2}{*}{ Sex of child } & Male & 19.6 & 13.3 & 7.1 & 20.3 & 39.7 \\
\hline & & Female & 12.8 & 10.7 & 6.2 & 19.6 & 50.7 \\
\hline & \multirow{3}{*}{ Age of child } & 5 and under & 19.5 & 13.2 & 7.0 & 20.1 & 40.2 \\
\hline & & 6 to 10 & 18.9 & 13.0 & 7.0 & 20.1 & 41.1 \\
\hline & & 11 and over & 12.3 & 10.4 & 6.1 & 19.2 & 52.0 \\
\hline \multirow{8}{*}{$\begin{array}{l}\text { Clinical } \\
\text { characteristics }\end{array}$} & \multirow{2}{*}{$\begin{array}{l}\text { Perceived control of child's } \\
\text { asthma }\end{array}$} & Less controlled & 17.9 & 12.7 & 6.9 & 20.1 & 42.3 \\
\hline & & More controlled & 16.5 & 12.2 & 6.8 & 20.1 & 44.5 \\
\hline & \multirow{2}{*}{$\begin{array}{l}\text { Child has another chronic } \\
\text { disease }\end{array}$} & No & 17.2 & 12.5 & 6.9 & 20.3 & 43.1 \\
\hline & & Yes & 7.8 & 8.0 & 5.0 & 17.6 & 61.6 \\
\hline & \multirow{2}{*}{$\begin{array}{l}\text { Child was vaccinated against } \\
\text { influenza last year }\end{array}$} & No & 20.6 & 14.3 & 7.7 & 21.4 & 36.0 \\
\hline & & Yes & 6.7 & 7.5 & 4.9 & 17.9 & 63.0 \\
\hline & \multirow{2}{*}{$\begin{array}{l}\text { Consultation with a health } \\
\text { professional }\end{array}$} & No & 22.7 & 14.3 & 7.4 & 20.4 & 35.2 \\
\hline & & Yes & 13.9 & 11.3 & 6.5 & 20.1 & 48.2 \\
\hline \multirow[t]{11}{*}{ Risk perception } & \multirow{3}{*}{ Level of general anxiety } & Lower & 18.5 & 12.8 & 6.9 & 20.1 & 41.7 \\
\hline & & Average & 19.8 & 13.2 & 7.1 & 20.1 & 39.8 \\
\hline & & Higher & 5.9 & 6.5 & 4.3 & 15.8 & 67.5 \\
\hline & \multirow{3}{*}{$\begin{array}{l}\text { Level of concern regarding } \\
\text { COVID-19 }\end{array}$} & Lower & 26.7 & 15.1 & 7.6 & 19.8 & 30.8 \\
\hline & & Average & 13.2 & 10.9 & 6.3 & 19.8 & 49.8 \\
\hline & & Higher & 17.2 & 12.5 & 6.9 & 20.4 & 43.0 \\
\hline & \multirow{2}{*}{$\begin{array}{l}\text { Perceived control of child's risk } \\
\text { of infection with COVID-19 }\end{array}$} & Less controlled & 17.2 & 12.4 & 6.8 & 20.1 & 43.5 \\
\hline & & More controlled & 16.6 & 12.2 & 6.8 & 20.0 & 44.5 \\
\hline & \multirow{3}{*}{$\begin{array}{l}\text { Perceived risks of infection with } \\
\text { COVID-19 }\end{array}$} & $50 \%$ & 19.0 & 13.1 & 7.0 & 20.2 & 40.7 \\
\hline & & Less than $50 \%$ & 14.7 & 11.5 & 6.5 & 19.9 & 47.4 \\
\hline & & More than $50 \%$ & 16.6 & 12.3 & 6.8 & 20.1 & 44.2 \\
\hline \multirow{6}{*}{$\begin{array}{l}\text { Cognitive } \\
\text { characteristics }\end{array}$} & \multirow{2}{*}{ Numeracy level } & Lower & 20.8 & 13.9 & 7.4 & 20.5 & 37.4 \\
\hline & & Higher & 10.7 & 9.8 & 5.9 & 19.3 & 54.2 \\
\hline & \multirow{2}{*}{ Cognitive skill } & Lower & 17.5 & 12.7 & 6.9 & 20.3 & 42.6 \\
\hline & & Higher & 13.9 & 11.2 & 6.4 & 19.9 & 48.6 \\
\hline & \multirow{2}{*}{ Risk tolerance } & Aversion & 18.2 & 12.7 & 6.9 & 20.1 & 42.1 \\
\hline & & Propensity & 12.8 & 10.6 & 6.2 & 19.4 & 51.1 \\
\hline
\end{tabular}


The next recursive model with the ordered probit reverses the direction of causality from parent to child. As shown in Table A1 in the Appendix, some exogenous variables, seen with the SUR specification, explain the parents' decision to accept a vaccine. Still, the predicted values of their decision in the child equation are not statistically significant. This last result bolsters the reverse causality model running from child to parents presented above.

\section{Discussion}

\section{Summary of results}

The development of a vaccine is an essential step in the effort to end the current COVID-19 pandemic. However, in this study, $19.1 \%$ of parents of children with asthma said they were "unlikely" or "very unlikely" to have their child vaccinated if a vaccine was available, and $21.0 \%$ said they were "unlikely" or "very unlikely" to get vaccinated themselves. These findings echo growing concern about support for COVID-19 vaccination, even among parents of children with chronic diseases $(40,41)$.

A major finding of this study emphasizes that household vaccination decisions revolve around the child. Once parents decide to have their child vaccinated, there is a high probability that they, too, will get vaccinated. Other studies in health prevention have shown similar results. Whether it's bicycle helmet use (42) or oral health habits (43), the presence of a child in the household helped parents change their own health behaviors.

We found that higher parental educational achievement was associated with a greater intention to have a child vaccinated. This is similar to other reports on vaccination $(14,41)$. Interestingly, this effect is independent and of greater importance than the numeracy level variable or the cognitive test score ("slow" vs. "fast" thinking), which did not emerge as significant predictors. It is possible that this difference in level of education extends beyond education itself and may represent the propensity of some segments of the population to share misinformation. This social contagion effect has also been observed in other vaccine refusal or hesitancy cases clustered either geographically or in specific religious or political groups $(16,44)$.

Parents who were active in the workforce were more likely to report the intention to vaccinate their child. The considerable potential impact on their income and disruption of their daily lives if they or their child were infected with COVID-19 could be a major factor in their decision (45).

Parents of girls were also more likely to have their child vaccinated. Parents' perception of the risks of their child being infected varied from $23.2 \%$ for a boy to $14.4 \%$ for a girl (results not presented). This may stem from differential risk perception and risk protection behavior from parents between girls and boys $(46,47)$.

While a child's asthma control level did not influence the likelihood of parents wanting to have their child vaccinated, parents of a child with another chronic disease were more likely to have their child vaccinated against COVID-19 (predicted probability of "very likely": $61.6 \%$ vs. $43.1 \%$ ). This result is consistent with the idea that parents of a child with another chronic disease may perceive their child as more fragile and more likely to suffer a severe case of COVID-19. 
We observed a strong correlation between the intention to have a child vaccinated against COVID-19 with a child's past vaccination with the influenza vaccine. The predicted probability of being "very likely" to have one's child vaccinated went from $36.0 \%$ when the child was not vaccinated against the influenza virus last year to $63.0 \%$ when the child was vaccinated. This finding suggests that we can apply (or at least be inspired by) some of the lessons learned from previous studies on the influenza vaccine regarding vaccine acceptance $(10,11)$.

Finally, similar to studies done with children in general and with children with asthma in particular, contact with a health care provider was a strong predictor of parents' intent to have their children vaccinated (26). Despite the diversity of information sources available to families, health professionals are still perceived by many as the most trusted source of health information. This may reflect the fact that those families have had the opportunity to have their concerns heard, their questions answered, or their myths about COVID-19 vaccination dispelled by health care providers. It may also be due to messages being tailored to individual families, leading to greater acceptance of vaccines than can be achieved through general public health messages. These findings underscore the importance of ensuring families have access to health care professionals and of equipping health care workers with the tools required to appropriately inform families and answer their questions and concerns.

\section{Notable negative findings}

This study did not find a significant effect of parental sex, age, or COVID-19-related level of concern. Those variables' previously documented effects could have been due to other factors of concern, such as parental anxiety level. Perceived risk of infection, numeracy, cognitive reflection test score, and general risk tolerance were also not statistically significant in our study.

Regarding risk tolerance, it is possible that the null impact observed is a combination of opposite effects. Indeed, while risk-averse parents want to have their child vaccinated to avoid the risk of infection, they may also have concerns about a new vaccine and want to avoid the potential risks of vaccination. Parental anxiety may show a similar pattern of mixed-effects leading to a non-statistically significant effect on vaccination intention.

\section{Limitations}

Our study is based on a hypothetical question about a vaccine that was not yet available at the time of the survey. Reported intention to vaccinate could change as the pandemic evolves, with a vaccine for COVID-19 now becoming available for adults (no vaccines have yet been studied or approved for children under age 16). Nevertheless, as research for a vaccine continues and COVID-19 cases, hospitalizations, and deaths continue to rise, there is a strong need to educate the general public, actively fight misinformation, and work on public acceptance of a COVID-19 vaccine.

It is also possible that the ongoing second (and prospect of a third) wave of the pandemic may have shifted the balance between risk and benefits for some families with regards to vaccination and would affect our estimates, were the study to be conducted now. 
Our sample was limited by the size of the number of patients followed in the clinic. It is possible that some factors with small or no effects may have been found to be not statistically significant in this study due to the sample size.

Our study was also conducted with parents of children with at least one underlying chronic condition (asthma) and many parents with a high education level. However, we think that vaccine acceptance is, if anything, probably higher in this subgroup, given previous reports (18) and our findings that parents of children with other chronic diseases were more likely to report wanting to get vaccinated. As such, $20 \%$ of parents unlikely to have their child vaccinated may represent an underestimation at the level of the general population.

\section{Conclusion}

As previous research indicates that vaccine uptake remains variable and inconsistent, successful vaccination against this disease will require widespread public education campaigns regarding vaccine safety and efficacy (48).

Now that a vaccine for COVID-19 has become available for adults (though it has yet to be studied or approved for children under age 16), our result linking parental vaccination first to child welfare and safety might enhance the acceptance of the vaccine by parents.

\section{Declarations}

\section{Ethics approval and consent to participate}

The ethics committee of the CHU Sainte-Justine approved the study (\#2021-3032) and informed consent (electronic consent) were obtained from all the participants before completing the online questionnaire.

\section{Competing interests to declare}

The authors declare that they have not competing interest

\section{Funding}

This study was supported by a grant from the Centre interuniversitaire de recherche en analyse des organisations (CIRANO) and from the Fonds de recherche du Québec-Santé (OD is chercheur-boursier clinicien Junior 1 of the FRQS)

\section{Acknowledgements}

None 


\section{Appendix}

Table A1. Recursive ordered probit models (parents $\rightarrow$ child)

\begin{tabular}{|c|c|c|c|c|c|c|}
\hline & & & \multicolumn{2}{|c|}{ Parent's model } & \multicolumn{2}{|c|}{ Child's model } \\
\hline & & & Coef. & $\mathrm{p}$ & Coef. & $\mathrm{p}$ \\
\hline \multicolumn{3}{|c|}{ Parents' intention to receive vaccine against COVID (linear prediction) } & \multicolumn{2}{|c|}{ Not included } & -0.864 & 0.771 \\
\hline \multirow{10}{*}{$\begin{array}{l}\text { Sociodemographic } \\
\text { characteristics }\end{array}$} & Sex of parent (ref.: Male) & Female & 0.361 & 0.218 & 0.731 & 0.49 \\
\hline & \multirow{2}{*}{ Age of parent (ref.: Under 35) } & 35 to 44 & 0.119 & 0.433 & 0.147 & 0.71 \\
\hline & & 45 and over & -0.122 & 0.535 & -0.278 & 0.499 \\
\hline & \multirow{2}{*}{ Level of education (ref.: Secondary or less) } & $\begin{array}{l}\text { College } \\
\text { (CEGEP) }\end{array}$ & 0.189 & 0.42 & 0.335 & 0.587 \\
\hline & & University & 0.576 & 0.001 & 1.056 & 0.532 \\
\hline & Employment status (ref.: Inactive) & Active & 0.507 & 0.003 & 1.038 & 0.484 \\
\hline & Region of residence (ref.: Other region) & Montreal & 0.208 & 0.128 & 0.399 & 0.535 \\
\hline & Sex of child (ref.: Male) & Female & Not & uded & 0.341 & 0.019 \\
\hline & \multirow{2}{*}{ Age of child (ref.: 5 and under) } & 6 to 10 & \multirow{2}{*}{\multicolumn{2}{|c|}{ Not included }} & 0.03 & 0.867 \\
\hline & & 11 and over & & & 0.37 & 0.097 \\
\hline \multirow{4}{*}{$\begin{array}{l}\text { Clinical } \\
\text { characteristics }\end{array}$} & $\begin{array}{l}\text { Perceived control of child's asthma (ref.: Less } \\
\text { controlled) }\end{array}$ & More controlled & \multicolumn{2}{|c|}{ Not included } & 0.067 & 0.744 \\
\hline & Child has another chronic disease (ref.: No) & Yes & \multicolumn{2}{|c|}{ Not included } & 0.571 & 0.028 \\
\hline & $\begin{array}{l}\text { Child was vaccinated against influenza last year } \\
\text { (ref:: No) }\end{array}$ & Yes & \multicolumn{2}{|c|}{ Not included } & 0.795 & $<0.001$ \\
\hline & Consultation with a health professional (ref.: No) & Yes & \multicolumn{2}{|c|}{ Not included } & 0.404 & 0.009 \\
\hline \multirow{7}{*}{ Risk perception } & \multirow{2}{*}{ Level of general anxiety (ref.: Lower) } & Average & -0.025 & 0.883 & -0.059 & 0.758 \\
\hline & & Higher & 0.382 & 0.115 & 0.818 & 0.48 \\
\hline & \multirow{2}{*}{$\begin{array}{l}\text { Level of concern regarding COVID-19 (ref.: } \\
\text { Lower) }\end{array}$} & Average & 0.335 & 0.099 & 0.604 & 0.547 \\
\hline & & Higher & 0.354 & 0.082 & 0.394 & 0.704 \\
\hline & $\begin{array}{l}\text { Know someone that has been affected by } \\
\text { COVID-19 (ref.: No) }\end{array}$ & Yes & -0.048 & 0.723 & \multicolumn{2}{|c|}{ Not included } \\
\hline & $\begin{array}{l}\text { Perceived control of child's risk of infection with } \\
\text { COVID-19 (ref.: Less controlled) }\end{array}$ & More controlled & \multicolumn{2}{|c|}{ Not included } & 0.029 & 0.837 \\
\hline & $\begin{array}{l}\text { Perceived risks of infection with COVID-19 (ref.: } \\
50 \% \text { ) }\end{array}$ & Less than $50 \%$ & \multicolumn{2}{|c|}{ Not included } & 0.209 & 0.189 \\
\hline \multirow{5}{*}{$\begin{array}{l}\text { Cognitive } \\
\text { characteristics }\end{array}$} & Numeracy level (ref.: Lower) & Higher & 0.356 & 0.023 & 0.516 & 0.627 \\
\hline & Cognitive skill (ref.: Lower) & Higher & 0.128 & 0.466 & 0.185 & 0.644 \\
\hline & Risk tolerance (ref.: Aversion) & Propensity & 0.082 & 0.59 & 0.28 & 0.333 \\
\hline & & g pseudolikelihood & \multicolumn{2}{|c|}{-404} & \multicolumn{2}{|c|}{-384} \\
\hline & & Pseudo R2 & \multicolumn{2}{|c|}{0.062} & \multicolumn{2}{|c|}{0.114} \\
\hline
\end{tabular}




\section{References}

1. Callaway E. The race for coronavirus vaccines: a graphical guide. Nature. 2020;580(7805):576.

2. Omer SB, Salmon DA, Orenstein WA, Dehart MP, Halsey N. Vaccine refusal, mandatory immunization, and the risks of vaccine-preventable diseases. New England Journal of Medicine. 2009;360(19):1981-8.

3. Lazarus JV, Ratzan SC, Palayew A, Gostin LO, Larson HJ, Rabin K, et al. A global survey of potential acceptance of a COVID-19 vaccine. Nature Medicine. 2020:1-4.

4. Dudley MZ, Halsey NA, Omer SB, Orenstein WA, T O'Leary S, Limaye RJ, et al. The state of vaccine safety science: Systematic reviews of the evidence. The Lancet Infectious Diseases. 2020.

5. Kim JJ. The role of cost-effectiveness in US vaccination policy. New England Journal of Medicine. 2011;365(19):1760-1.

6. Maglione MA, Das L, Raaen L, Smith A, Chari R, Newberry S, et al. Safety of vaccines used for routine immunization of US children: a systematic review. Pediatrics. 2014;134(2):325-37.

7. Control CfD, Prevention. Ten great public health achievements--United States, 2001-2010. MMWR Morbidity and mortality weekly report. 2011;60(19):619.

8. Streefland P, Chowdhury A, Ramos-Jimenez P. Patterns of vaccination acceptance. Social science \& medicine. 1999;49(12):1705-16.

9. Szilagyi PG, Albertin CS, Gurfinkel D, Saville AW, Vangala S, Rice JD, et al. Prevalence and characteristics of HPV vaccine hesitancy among parents of adolescents across the US. Vaccine. 2020;38(38):6027-37.

10. Schmid P, Rauber D, Betsch C, Lidolt G, Denker M-L. Barriers of influenza vaccination intention and behavior-a systematic review of influenza vaccine hesitancy, 2005-2016. PloS one. 2017;12(1):e0170550.

11. Hofstetter AM, Robinson JD, Lepere K, Cunningham M, Etsekson N, Opel DJ. Clinician-parent discussions about influenza vaccination of children and their association with vaccine acceptance. Vaccine. 2017;35(20):2709-15.

12. Fisher KA, Bloomstone SJ, Walder J, Crawford S, Fouayzi H, Mazor KM. Attitudes toward a potential SARS-CoV-2 vaccine: a survey of US adults. Annals of internal medicine. 2020.

13. Kreps S, Prasad S, Brownstein JS, Hswen Y, Garibaldi BT, Zhang B, et al. Factors Associated With US Adults' Likelihood of Accepting COVID-19 Vaccination. JAMA Network Open. 2020;3(10):e2025594-e.

14. Bell S, Clarke R, Mounier-Jack S, Walker JL, Paterson P. Parents' and guardians' views on the acceptability of a future COVID-19 vaccine: A multi-methods study in England. Vaccine. 2020;38(49):7789-98.

15. Butter S, McGlinchey E, Berry E, Armour C. Psychological, social, and situational factors associated with COVID-19 vaccination intentions: A study of UK key workers and non-key workers. 2020.

16. Duquette N. Heard immunity: effective persuasion for a future COVID-19 vaccine. 2020. 
17. Head KJ, Kasting ML, Sturm LA, Hartsock JA, Zimet GD. < ? covid19?> A National Survey Assessing SARS-CoV-2 Vaccination Intentions: Implications for Future Public Health Communication Efforts. Science Communication. 2020;42(5):698-723. 18. Goldman RD, Yan TD, Seiler M, Cotanda CP, Brown JC, Klein EJ, et al. Caregiver willingness to vaccinate their children against COVID-19: Cross sectional survey. Vaccine. 2020;38(48):7668-73.

19. Reiter PL, Pennell ML, Katz ML. Acceptability of a COVID-19 vaccine among adults in the United States: How many people would get vaccinated? Vaccine. 2020;38(42):6500-7.

20. Goldman RD, McGregor S, Marneni SR, Katsuta T, Griffiths MA, Hall JE, et al. Willingness to vaccinate children against influenza after the Coronavirus disease 2019 pandemic. The Journal of pediatrics. 2020.

21. Sokol RL, Grummon AH. COVID-19 and parent intention to vaccinate their children against influenza. Pediatrics. 2020;146(6).

22. Rhodes A, Hoq M, Measey M-A, Danchin M. Intention to vaccinate against COVID-19 in Australia. The Lancet Infectious Diseases. 2020.

23. Asher I, Pearce N. Global burden of asthma among children. The international journal of tuberculosis and lung disease. 2014;18(11):1269-78.

24. Ismaila AS, Sayani AP, Marin M, Su Z. Clinical, economic, and humanistic burden of asthma in Canada: a systematic review. BMC pulmonary medicine. 2013;13(1):70.

25. Soyer OU, Hudaverdiyev S, Civelek E, Isik E, Karabulut E, Kocabas C, et al. Parental perspectives on influenza vaccination in children with asthma. Pediatric pulmonology. 2011;46(2):139-44.

26. Gnanasekaran SK, Finkelstein JA, Hohman K, O'Brien M, Kruskal B, Lieu TA. Parental perspectives on influenza vaccination among children with asthma. Public health reports. 2006;121(2):181-8.

27. Buyuktiryaki B, Soyer OU, Erkocoglu M, Dogan A, Azkur D, Kocabas CN, et al. What a pandemic teaches us about vaccination attitudes of parents of children with asthma. Vaccine. 2014;32(20):2275-80.

28. Betsch C, Böhm R, Chapman GB. Using behavioral insights to increase vaccination policy effectiveness. Policy Insights from the Behavioral and Brain Sciences. 2015;2(1):61-73.

29. Schoch-Spana M, Brunson EK, Long R, Ruth A, Ravi SJ, Trotochaud M, et al. The public's role in COVID-19 vaccination: Human-centered recommendations to enhance pandemic vaccine awareness, access, and acceptance in the United States. Vaccine. 2020. 30. Organization WH. Behavioural considerations for acceptance and uptake of COVID19 vaccines: WHO technical advisory group on behavioural insights and sciences for health, meeting report, 15 October 2020. 2020.

31. Löwe B, Decker O, Müller S, Brähler E, Schellberg D, Herzog W, et al. Validation and standardization of the Generalized Anxiety Disorder Screener (GAD-7) in the general population. Medical care. 2008:266-74.

32. Cao W, Fang Z, Hou G, Han M, Xu X, Dong J, et al. The psychological impact of the COVID-19 epidemic on college students in China. Psychiatry research. 2020;287:112934. 
33. Johnson SU, Ulvenes PG, Øktedalen T, Hoffart A. Psychometric properties of the general anxiety disorder 7-item (GAD-7) scale in a heterogeneous psychiatric sample. Frontiers in psychology. 2019;10:1713.

34. $\mathrm{Wu} \mathrm{Z,} \mathrm{McGoogan} \mathrm{JM.} \mathrm{Characteristics} \mathrm{of} \mathrm{and} \mathrm{important} \mathrm{lessons} \mathrm{from} \mathrm{the} \mathrm{coronavirus}$ disease 2019 (COVID-19) outbreak in China: summary of a report of 72314 cases from the Chinese Center for Disease Control and Prevention. Jama. 2020;323(13):1239-42. 35. Lavoie KB, S The International Assessment of COVID-19-related Attitudes, Concerns, Responses and Impacts in Relation to Public Health Policies (iCARE) study: Can we optimise strategies to flatten the COVID-19 infection curve? 2020 [Available from: https://mbmc-cmcm.ca//r/covid19/].

36. Wallston KA, Strudler Wallston B, DeVellis R. Development of the multidimensional health locus of control (MHLC) scales. Health education monographs. 1978;6(1):160-70.

37. Frederick S. Cognitive reflection and decision making. Journal of Economic perspectives. 2005;19(4):25-42.

38. Kahneman D. Thinking, fast and slow: Macmillan; 2011.

39. Jappelli T. Economic literacy: An international comparison. The Economic Journal. 2010;120(548):F429-F51.

40. de Figueiredo A, Simas C, Karafillakis E, Paterson P, Larson HJ. Mapping global trends in vaccine confidence and investigating barriers to vaccine uptake: a large-scale retrospective temporal modelling study. The Lancet. 2020;396(10255):898-908.

41. Goldman RD, Staubli G, Cotanda CP, Brown JC, Hoeffe J, Seiler M, et al. Factors associated with parents' willingness to enroll their children in trials for COVID-19 vaccination. Human Vaccines \& Immunotherapeutics. 2020:1-5.

42. Richard J-B, Thelot B, Beck F. Evolution of bicycle helmet use and its determinants in France: 2000-2010. Accident Analysis \& Prevention. 2013;60:113-20.

43. Tolvanen M, Anttonen V, Mattila M-L, Hausen H, Lahti S. Influence of children's oral health promotion on parents' behaviours, attitudes and knowledge. Acta Odontologica Scandinavica. 2016;74(5):321-7.

44. Thunstrom L, Ashworth M, Finnoff D, Newbold S. Hesitancy Towards a COVID-19 Vaccine and Prospects for Herd Immunity. Available at SSRN 3593098. 2020.

45. Esposito S, Marchisio P, Bosis S, Lambertini L, Claut L, Faelli N, et al. Clinical and economic impact of influenza vaccination on healthy children aged 2-5 years. Vaccine. 2006;24(5):629-35.

46. Alan S, Baydar N, Boneva T, Crossley TF, Ertac S. Transmission of risk preferences from mothers to daughters. Journal of Economic Behavior \& Organization. 2017;134:6077.

47. Morrongiello BA, Dawber T. Parental influences on toddlers' injury-risk behaviors: are sons and daughters socialized differently? Journal of Applied Developmental Psychology. 1999;20(2):227-51.

48. Dror AA, Eisenbach N, Taiber S, Morozov NG, Mizrachi M, Zigron A, et al. Vaccine hesitancy: the next challenge in the fight against COVID-19. European journal of epidemiology. 2020;35(8):775-9. 